
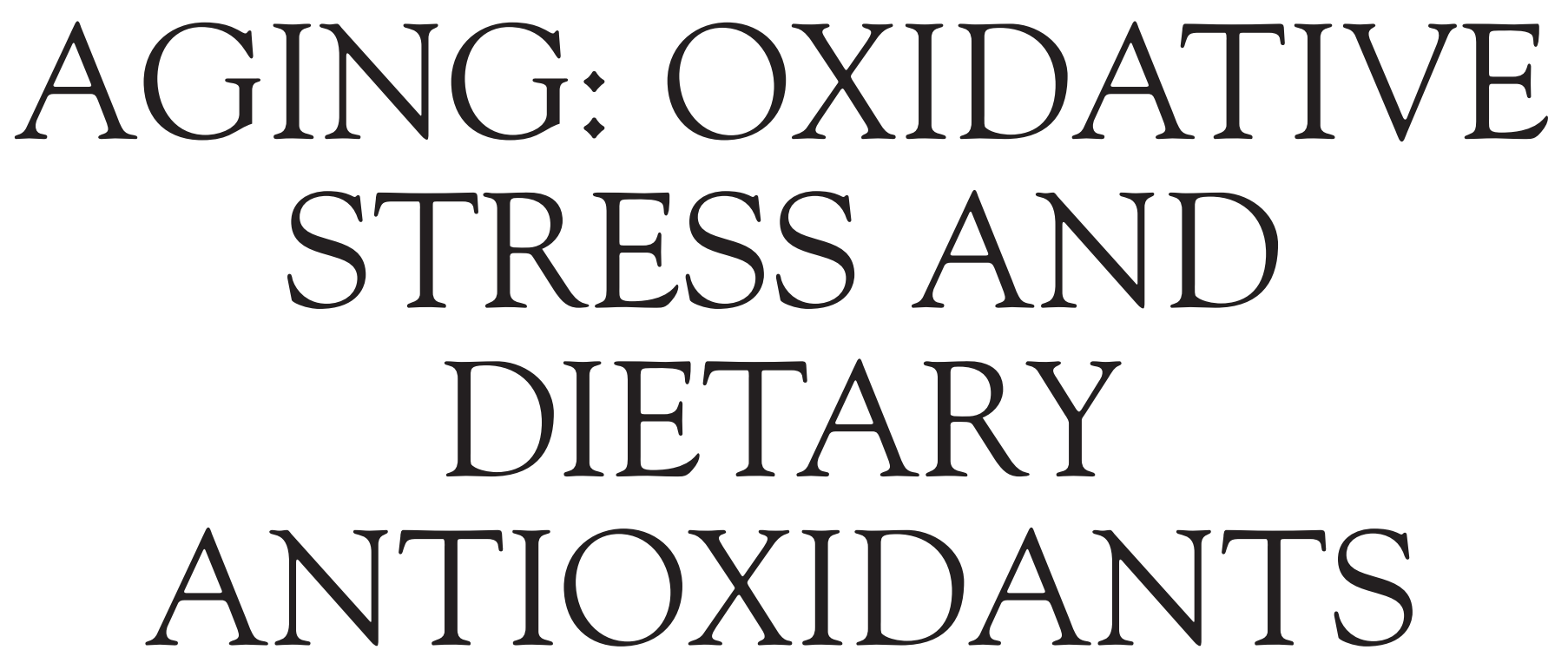

Edited by

Victor R. PREEDY

King's College London,

London, UK 


\title{
Magnesium, Oxidative Stress, and Aging Muscle
}

\author{
Mario Barbagallo, Ligia J. Dominguez
}

Geriatric Unit, Department of Internal Medicine DIBIMIS, University of Palermo, Italy

\section{List of Abbreviations}

ATP adenosine triphosphate

Ca calcium

cAMP cyclic adenosine monophosphate

CRP C-reactive protein

DNA deoxyribonucleic acid

IFN interferon

Ig immunoglobulin

IL interleukin

K potassium

MAPK mitogen-activated protein kinase

MDA malondialdehyde

Mg magnesium

MgT total serum $\mathrm{Mg}$ concentrations

NADPH nicotinamide adenine dinucleotide phosphate

NFкB activation of nuclear factor-kappaB

NHANES National Health and Nutrition

NMDA $N$-methyl-D-aspartate

PAI plasminogen activator inhibitor

PMN polymorphonuclear

PTH parathyroid hormone

RBCs red blood cells

RDA recommended dietary allowance

RNA ribonucleic acid

ROS reactive oxygen species

TNF tumor necrosis factor

VCAM vascular cell adhesion molecule

\section{INTRODUCTION}

In recent decades the clinical relevance and biologic significance of magnesium $(\mathrm{Mg})$ have been extensively documented. However, the role of $\mathrm{Mg}$ in medicine started as far back as the 17th century covering a large span of the chemical and pharmacologic fields of knowledge. The recognition by Grew, in 1695, that magnesium sulfate is one of the essential constituents of Epsom salt, may be considered the entry of magnesium into medicine. ${ }^{1}$

The Mg ion, the second most abundant intracellular cation after potassium, plays essential roles in the structure and function of the human body; it is an essential cofactor in a wide variety of biologic processes, including protein synthesis, nucleic acid synthesis and stability, neuromuscular excitability and the conduction of neural impulses, stimulus-contraction coupling and muscle contraction. ${ }^{2,3}$ In particular, it is now clear that the $\mathrm{Mg}$ ion, although not directly involved in the biochemical process of contraction, modulates vascular smooth muscle tone and contractility by affecting calcium ion concentrations and the availability of the calcium ion at critical sites. Magnesium serves to actively promote relaxation, offset calciumrelated excitation-contraction coupling and decrease cellular responsiveness to depolarizing stimuli by different mechanisms: (i) stimulating Ca-dependent $\mathrm{K}$ channels; (ii) competitively inhibiting calcium (Ca) binding to calmodulin; (iii) stimulating both plasma membrane and sarcoplasmic reticulum Ca ATPases; and (iv) activating the membrane $\mathrm{Na}, \mathrm{K}$-ATPase pump. ${ }^{2,4}$ Magnesium is a critical modulator of the tension with which the contractile apparatus of striated muscle responds to the prevailing ionized calcium concentration; the $\mathrm{Mg}$ complex with adenosine triphosphate (MgATP) is the substrate for the enzymatic reactions that underlie the sliding filament mechanism for myofibrillar contraction and relaxation. Magnesium also participates in many of the most vital oxidative, synthetic, and transport processes of the muscle cell. Consistent with the above, calcium-induced contraction in muscles is not only sensitive to changes in $\mathrm{Mg}$ concentration, but direct reduction of extracellular $\mathrm{Mg}$ raises smooth muscle $\mathrm{Ca}$ content, while conversely, elevations in $\mathrm{Mg}$ concentrations reciprocally lower calcium content in muscle. ${ }^{5}$ Magnesium is an indispensable part of the activated MgATP complex, and it is required for adenosine triphosphate (ATP) synthesis in the mitochondria. ${ }^{2,3}$ Cell signaling requires MgATP for the phosphorylation of proteins and the synthesis and activation of the cell-signaling molecule cyclic adenosine monophosphate (cAMP), involved in multiple biochemical processes. Magnesium is a necessary cofactor in over 300 enzymatic reactions; it is required for the activity of 
TABLE 16.1 Physiological Role of Magnesium in the Body

\begin{tabular}{ll}
\hline ENZYME FUNCTION & \\
\hline Enzyme Substrate & Direct Enzyme Activation \\
- Kinases & - Phosphofructokinase \\
- ATPases/GTPases & - Creatine kinase \\
- Cyclases & - 5-Phosphoribosyl- \\
& pyrophosphate synthetase \\
& - Adenylate cyclase \\
& - Na-K-ATPase
\end{tabular}

\begin{tabular}{ll}
\hline STRUCTURAL FUNCTION & \\
\hline - Proteins & \\
- Polyribosomes & - Multiple enzyme complexes \\
- Nucleic acids & Mitochondria \\
\hline
\end{tabular}

CALCIUM ANTAGONIST

- Muscle contraction/relaxation

- Neurotransmitter release

- Action potential

conduction in nodal tissue

MEMBRANE FUNCTION

- Cell adhesion

- Transmembrane electrolyte flux

all rate-limiting glycolytic enzymes, protein kinases, and, more generally, all ATP and phosphate transfer-associated enzymes. Magnesium may also bind the enzymes directly (i.e. RNA and DNA polymerases) and alter their structure. ${ }^{2,3}$ Therefore, the availability of an adequate quantity of $\mathrm{Mg}$ may be considered a critical factor for normal cellular and body homeostasis and function (Table 16.1).

\section{MAGNESIUM METABOLISM IN OLDER ADULTS}

The adult human body contains approximately $24 \mathrm{~g}$ (1 $\mathrm{mol}$ ) of $\mathrm{Mg}$, of which about $65 \%$ resides in the mineral phase of bone, about $27 \%$ is found in muscle, and $6-7 \%$ is found in other cells. Extracellular Mg accounts for only $1 \%$ or so of total body $\mathrm{Mg}$. The normal serum $\mathrm{Mg}$ concentration ranges from 0.75 to $0.95 \mathrm{mmol} / \mathrm{L}(1.7-2.5 \mathrm{mg} /$ $\mathrm{dL}$ or $1.5-1.9 \mathrm{meq} / \mathrm{L}$ ) and is tightly controlled and maintained in this range. In the serum, about $70-80 \%$ of $\mathrm{Mg}$ exists in the biologically active ionized (free) form, while the remainder is bound to circulating proteins (e.g. albu$\min )(20-30 \%)$ or complexed to anions (e.g. bicarbonate, phosphate) (1\%). The cytosolic $\mathrm{Mg}$ concentration ranges between 0.5 and $1.0 \mathrm{mmol} / \mathrm{L}$ in various types of cell 2,6 (Tables 16.2 and 16.3). The magnesium status in the body is determined mainly by absorption through the gastrointestinal tract, the requirement of different tissues (i.e. skeletal and cardiac muscle uptake and usage), and renal excretion. The small intestine is the main site for $\mathrm{Mg}$ absorption. Healthy individuals need to ingest $0.15-0.2$ $\mathrm{mmol} / \mathrm{kg} /$ day to stay in balance. The kidney exerts the
TABLE 16.2 Characteristics of Ionic Magnesium

\begin{tabular}{ll}
\hline Element category & Alkaline earth metal \\
Atomic number & 12 \\
Atomic weight & $24.305 \mathrm{~g} / \mathrm{mol}$ \\
Valence & 2 \\
Normal serum & $0.75-0.95 \mathrm{mmol} / \mathrm{L}$ \\
& $1.7-2.5 \mathrm{mg} / \mathrm{dL}$ \\
Total body content & $24 \mathrm{~g}$ \\
Distribution in serum & - free ionized $70-80 \%$ \\
& - protein-bound $20-30 \%$ \\
& - complexed $1 \%$ \\
\hline
\end{tabular}

TABLE 16.3 Magnesium Equilibrium

- Main determinants are gastrointestinal absorption and renal excretion

- Healthy individuals need to ingest $0.2-0.4 \mathrm{mmol} / \mathrm{kg}$ of body weight/day to stay in balance

- Extracellular $\mathrm{Mg}$ is in equilibrium with that in the bone, kidneys, intestine, and other soft tissues

- Bone is the main reservoir of $\mathrm{Mg}$

- Primary renal disorders cause hypomagnesemia by decreased tubular reabsorption of $\mathrm{Mg}$

- Osmotic diuresis results in magnesium loss

- Drugs may cause magnesium wasting

most predominant impact in controlling body $\mathrm{Mg}$ status. Diuretics, frequently used in older populations, may also modify renal $\mathrm{Mg}$ handling, reducing $\mathrm{Mg}$ reabsorption. 2,6

Bone is the main storage location of $\mathrm{Mg}$, which cannot be quickly exchanged with the $\mathrm{Mg}$ in extracellular fluids; more prompt requirements for $\mathrm{Mg}$ are satisfied from the $\mathrm{Mg}$ stored in the intracellular compartment. There is wide-ranging variability in $\mathrm{Mg}$ intake, absorption, conservation, and excretion. Alterations in Mg metabolism that have been associated with aging include a reduction in $\mathrm{Mg}$ intake and intestinal absorption, and an increase in $\mathrm{Mg}$ urinary and fecal excretion (Figure 16.1). Although no known hormonal factor is specifically involved in the regulation of $\mathrm{Mg}$ metabolism, several hormones are recognized to have an effect on $\mathrm{Mg}$ balance and transport. Among them, parathyroid hormone (PTH), calcitonin, catecholamines, and insulin have a major role. ${ }^{2,6}$

One of the main reasons why $\mathrm{Mg}$ metabolism has not become a greater focus of routine attention in clinical practice has been the difficulties in obtaining an easily available, accurate, and reproducible measurement of $\mathrm{Mg}$ status in the body. Total serum $\mathrm{Mg}$ concentrations $(\mathrm{MgT})$ do not always reflect accurately the body $\mathrm{Mg}$ homeostasis; $\mathrm{MgT}$ has proved useful and it has been extensively utilized in epidemiologic studies, but it may not be helpful for the detection of a subclinical $\mathrm{Mg}$ deficit on an individual basis. MgT does not change with age, while intracellular free $\mathrm{Mg}$ tends to decrease with age. ${ }^{6}$ 


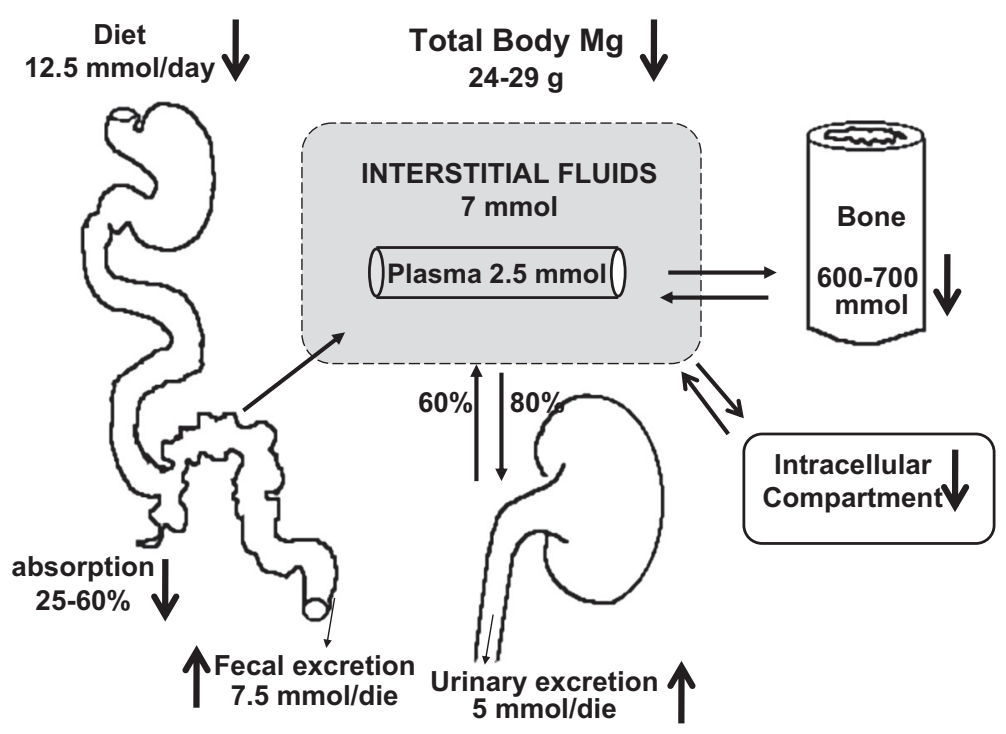

FIGURE 16.1 Magnesium homeostasis with age (arrows indicate possible sites of alteration with aging).

TABLE 16.4 Main Mechanisms of Magnesium Deficit with Aging

\section{PRIMARYMAGNESIUM DEFICIT}

- Inadequate $\mathrm{Mg}$ dietary intake

- Reduced efficiency of Mg absorption (associated with reduced vitamin D levels)

- Increased urinary excretion of $\mathrm{Mg}$ (associated with agedependent reduction of kidney function and of $\mathrm{Mg}$ tubular reabsorption)

\section{SECONDARY MAGNESIUM DEFICIENCY}

- Associated with age-related diseases and comorbidities

- Increased urinary Mg loss secondary to drugs (i.e. diuretics) frequently used in older persons

However, more precise and expensive techniques for measuring intracellular free $\mathrm{Mg}$ concentrations remain mainly at the research level, while available measurements of serum ionized free $\mathrm{Mg}$, the active part of serum $\mathrm{Mg}$, may still have some technical flaws. 2,6

Aging represents a major risk factor for $\mathrm{Mg}$ deficit. The total body $\mathrm{Mg}$ content and intracellular $\mathrm{Mg}$ tend to decrease with age. ${ }^{2}$ The most common mechanisms which may cause $\mathrm{Mg}$ deficits with aging are summarized in Table 16.4; ${ }^{6}$ they include primary $\mathrm{Mg}$ deficit (inadequate $\mathrm{Mg}$ nutrient intake, reduced efficiency of $\mathrm{Mg}$ absorption, and increased urinary excretion of $\mathrm{Mg}$ ), and secondary $\mathrm{Mg}$ deficiency (associated with drug use or pathologic conditions associated with aging).

\section{MAGNESIUM, MUSCULAR PERFORMANCE, AND AGING MUSCLE}

An adequate cellular $\mathrm{Mg}$ concentration seems necessary for maintaining optimal muscle performance and exercise tolerance. Magnesium status strongly affects muscle
TABLE 16.5 Mechanisms by Which Low Magnesium Status May Affect Muscle, Increasing Oxidative Stress

- Energetic metabolism (oxygen uptake and energy production)

- Transmembrane transport

- Muscle contraction and relaxation (by means of MgATP and the release of calcium)

performance, probably due to the key role of magnesium in energetic metabolism, transmembrane transport, and muscle contraction and relaxation. ${ }^{7}$ Magnesium is involved in numerous processes that affect muscle function, including oxygen uptake and energy production. Myofibrillar contraction and relaxation is strictly connected to $\mathrm{Mg}$ and $\mathrm{MgATP}$, as is the uptake and release of Ca from the sarcotubules. Thus, intracellular concentrations of $\mathrm{Mg}$, even within narrow limits, can profoundly affect the contractile performance of the muscle cell (Table 16.5).

Magnesium supplementation (up to $8 \mathrm{mg} / \mathrm{kg}$ daily) was shown to enhance muscle strength $(20 \%$ increase of peak knee-extension torque) in young individuals, ${ }^{8}$ improve endurance exercise performance, and decrease oxygen use during submaximal exercise. ${ }^{9}$ Exercise induces a redistribution of $\mathrm{Mg}$ in the body to accommodate metabolic needs, accounting for changes in $\mathrm{Mg}$ concentration in extracellular fluids, blood cellular components, myocytes, and adipocytes. It has been suggested that $\mathrm{Mg}$ deficiency may impair exercise performance and increase the oxidative stress linked to strenuous exercise. ${ }^{10}$ Conversely, exercise increases urinary and sweat losses of magnesium, and thus the $\mathrm{Mg}$ requirement is increased in an individual performing exercise. A low $\mathrm{Mg}$ intake in athletes may result in a Mg-deficient status, and may thus reduce their performance. Magnesium supplementation, or increased dietary intake, is beneficial to physically active persons with a low or deficient $\mathrm{Mg}$ status to enhance strength 
and to improve exercise performance. ${ }^{8,9}$ There is less evidence for $\mathrm{Mg}$ supplementation in physically active persons with an adequate $\mathrm{Mg}$ status for enhancing physical performance. ${ }^{10}$

A large portion of the energy used for physiologic functions in humans is produced by mitochondria through the movement of electrons in the respiratory chain. Magnesium in the mitochondria accounts for one third of total cellular $\mathrm{Mg}$; it is present as a complex with ATP and as a component of membranes and nucleic acids. Magnesium is critical for basic mitochondrial functions, including ATP synthesis, electron transport chain complex subunits, and oxygen detoxification. ${ }^{2,6}$ As discussed below, $\mathrm{Mg}$ seems fundamental for controlling oxidative stress and for the preservation of normally functioning muscle mitochondria. An inadequate availability of $\mathrm{Mg}$ may lead to reduced mitochondrial efficiency and increased production of reactive oxygen species (ROS), and subsequent structural and functional impairment of proteins that may lead to the decline in skeletal muscle mitochondrial function associated with aging in humans. ${ }^{11}$

In rats, $\mathrm{Mg}$ depletion is associated with structural damage to muscle cells, mitochondrial swelling and an altered ultrastructure that was shown to be associated with an increased production of ROS, lipid and protein damage, and impaired intracellular calcium homeostasis. Both $\mathrm{Mg}$ deficit and exercise contribute to the occurrence of oxidative stress. ${ }^{12}$ Although the importance of $\mathrm{Mg}$ as a determinant of muscle performance in young athletes is well established, its role in maintaining muscle integrity and function in older adults is largely unknown.

Lukaski and Nielsen ${ }^{7}$ examined the effects of different levels of dietary $\mathrm{Mg}$ on biochemical measures and physiologic responses in postmenopausal women (45 to 71 years old) during submaximal exercise, in relation to changes in erythrocyte and skeletal muscle $\mathrm{Mg}$ concentrations. The women consumed diets containing conventional foods with varying $\mathrm{Mg}$ content, totaling $112 \mathrm{mg} / 8.4 \mathrm{MJ}$ (2000 kcal) supplemented with $200 \mathrm{mg}$ of $\mathrm{Mg}$ daily for 35 days (control), then $112 \mathrm{mg} / 8.4 \mathrm{MJ}$ for 93 days (depletion) followed by $112 \mathrm{mg} / 8.4 \mathrm{MJ}$ supplemented with $200 \mathrm{mg}$ of $\mathrm{Mg}$ daily for 49 days (repletion), in a depletion-repletion experiment. The concentration of $\mathrm{Mg}$ in erythrocytes, $\mathrm{Mg}$ retention, and skeletal muscle $\mathrm{Mg}$ content decreased when dietary $\mathrm{Mg}$ was restricted. Peak oxygen uptake, total and cumulative net oxygen uptake - determined by using indirect calorimetry and peak heart rate increased during standardized submaximal work with restricted compared with adequate dietary $\mathrm{Mg} .{ }^{7}$ These findings indicate that dietary $\mathrm{Mg}$ depletion, in otherwise healthy women, results in a significant increase in energy needs and adversely affects cardiovascular function during sub-maximal work. These data, showing a decreased work economy and functional impairment in older women on restricted dietary $\mathrm{Mg}$, extend the knowledge of magnesium status in young athletes to older women not participating in intense physical activity.

Older age is frequently characterized by sarcopenia, defined as a loss of skeletal muscle mass, quality, and function..$^{13}$ Sarcopenia of aging is almost a universal phenomenon, occurring in a wide range of species, from nematodes to flies, rodents, non-human primates, and humans. Muscle changes in humans start in the fourth decade of life. Sarcopenia in the aging population is a strong independent risk factor for disability and mortality. What gererally occurs with aging is a decrease in the rate of synthesis of several muscle proteins, specifically myosin heavy chain and mitochondrial proteins. The underlying causes of the reduction in mitochondrial activity and ATP production seem to be related to a decrease in mitochondrial DNA and in messenger RNA. Reduced ATP production has been suggested to be the basis of reduced muscle protein turnover, which requires energy ${ }^{13}$ (Table 16.6). Magnesium depletion, because of the fundamental role of $\mathrm{Mg}$ in the MgATP complex, may play a role in this phenomenon, causing structural damage in muscle cells through increased oxidative stress (see below) and impaired intracellular calcium homeostasis. Both aerobic exercise and resistance exercise enhance muscle protein synthesis and mitochondrial activity. We do not know the role of $\mathrm{Mg}$ in aging-related muscle mitochondrial dysfunction, or the role of reduced physical activity. Because $\mathrm{Mg}$ status is strictly related to muscle ATP, and both $\mathrm{Mg}$ deficiency and sarcopenia tend to be more prevalent at older ages, we hypothesized that poor $\mathrm{Mg}$ status contributes to late life sarcopenia. Using data from the InCHIANTI study, a well-characterized representative sample of older men and women, we found a significant, independent, and strong relationship between circulating $\mathrm{Mg}$ and muscle performance; this was consistent across several muscle performance parameters for both men and women, ${ }^{14}$ suggesting a role for $\mathrm{Mg}$ status in helping to maintain muscle function with age. As discussed below, in addition to the role of $\mathrm{Mg}$ in energetic metabolism, at least two other mechanisms may help to explain these findings: (i) increased oxidative stress in the presence of $\mathrm{Mg}$ deficiency, and (ii) the proinflammatory effect of $\mathrm{Mg}$ depletion.

TABLE 16.6 Effects of Aging on the Mitochondria by Which Oxidative Stress May Be Increased

- Decreased number

- Morphology modifications

- Increased DNA mutations

- Decreased biogenesis

- Decreased autophagy

- Increased apoptosis 


\section{MAGNESIUM, EXERCISE, AND OXIDATIVE STRESS}

Studies on cultured cells, in experimental animal models, and in humans, have consistently shown that $\mathrm{Mg}$ deficiency is associated with increased oxidative stress and decreased antioxidant defense. Several studies have shown convincingly that $\mathrm{Mg}$ deficiency results in increased production of oxygen-derived free radicals in various tissues, increased free-radical-elicited oxidative tissue damage, increased production of superoxide anion by inflammatory cells, decreased antioxidant enzyme expression and activity, decreased cellular and tissue antioxidant levels, and increased oxygen peroxide production. ${ }^{6,15-23}$ Magnesium deficiency in rats causes decreased hepatic glutathione, superoxide dismutase, and vitamin E, together with increased lipid peroxidation and malondialdehyde (MDA) levels secondary to upregulated nicotinamide adenine dinucleotide phosphate (NADPH) oxidase activity. ${ }^{24}$

In stroke-prone spontaneously hypertensive rats, $\mathrm{Mg}$ deficiency results in marked increases in oxidative stress, superoxide accumulation, mitogen-activated protein kinase (MAPK) activation, and the development of hypertension. ${ }^{25}$ Magnesium has antioxidant capacities and may prevent oxygen radical formation by scavenging free radicals and by inhibiting xanthine oxidase and NADPH oxidase. ${ }^{26}$ Magnesium supplementation may reduce oxidative stress. In experimental diabetes, a decreased intracellular Mg level and increased Mg urinary excretion were associated with increased plasma MDA and decreased expression of hepatic superoxide dismutase and glutathione S-transferase; all of these effects were corrected by Mg supplementation..$^{27}$

We have shown that antioxidant capacity and the action to reduce oxidative stress of glutathione and vitamin E (measured as decreased reduced/oxidized glutathione ratio, increased lipohydroperoxides, and increased thiobarbituric acid-reactive substances) are associated with an increase in the intracellular concentration of Mg. ${ }^{28,29}$

\section{MAGNESIUM, OXIDATIVE STRESS, AND THE AGING MUSCLE: THE ROLE OF INFLAMMATION}

A state of chronic inflammation has been proposed as one of the main causes of frailty in older persons. ${ }^{30}$ Poor Mg status may trigger the development of a proinflammatory state both by causing excessive production and release of IL- $1 \beta$ and TNF- $\alpha, 31$ and by elevating circulating concentrations of pro-inflammatory neuropeptides that trigger activation of low-grade chronic inflammation. ${ }^{32}$
Several interventional studies in animal models of $\mathrm{Mg}$ deficiency have provided convincing evidence of the link between $\mathrm{Mg}$, inflammation, and oxidative stress. Oxidative mitochondrial decay linked to aging may itself favor hypomagnesemia. Magnesium deficiency inhibits endothelial growth and migration, and it stimulates the synthesis of nitric oxide and some inflammatory markers, thus directly modulating microvascular functions. ${ }^{33,34}$ Experimental studies in rats have shown that $\mathrm{Mg}$ deficiency induces a chronic impairment of redox status associated with inflammation, which could contribute to increased oxidized lipids, and may promote hypertension and vascular disorders, ${ }^{35}$ confirming the link between oxidative stress and inflammation.

Several other experimental studies have demonstrated that $\mathrm{Mg}$ deprivation determines a pro-inflammatory state, confirmed by the elevated circulating plasma level of several markers of inflammation, including interleukin-6 (IL-6), IL-1 $\beta$, tumor necrosis factor (TNF)- $\alpha$, vascular cell adhesion molecule (VCAM), and plasminogen activator inhibitor (PAI)-1; other markers of inflammation, such as increased circulating inflammatory cells and increased hepatic production and release of acute phase proteins (i.e. complement, alpha2-macroglobulin, alpha1-acid glycoprotein, fibrinogen), have been reported as well. ${ }^{33-39} \mathrm{~A}$ direct mechanistic link has been reported for the association of low $\mathrm{Mg}$ and increased production and secretion of TNF- $\alpha$ and IL- $1 \beta$ in cultured alveolar macrophages. ${ }^{40}$

Because $\mathrm{Mg}$ acts as a natural calcium antagonist, the molecular basis for the inflammatory response may also be the result of a modulation of the intracellular calcium concentration. Potential mechanisms include the priming of phagocytic cells, the opening of calcium channels, activation of $N$-methyl-D-aspartate (NMDA) receptors, and / or the activation of nuclear factor-kappaB (NFKB) $)^{2,6}$

Studies in humans have confirmed the clinical relevance of the link between low serum Mg levels, as well as inadequate dietary $\mathrm{Mg}$, and low-grade systemic inflammation. $41-44$ Data from the Women's Health Study have shown that $\mathrm{Mg}$ intake is inversely related to systemic inflammation, measured by serum C-reactive protein concentrations, and to the prevalence of the metabolic syndrome in adult women. ${ }^{41}$ Likewise, using the 1999-2002 NHANES databases, King et al found that dietary $\mathrm{Mg}$ intake was inversely related to C-reactive protein levels. Among the $70 \%$ of the population not taking supplements, $\mathrm{Mg}$ intake below the RDA was significantly associated with a higher risk of having elevated C-reactive protein. ${ }^{42}$ Other clinical studies have suggested that serum $\mathrm{Mg}$ levels are also inversely related to oxidative stress and inflammation markers, including C-reactive protein and TNF- $\alpha$ concentrations. ${ }^{43,44}$ 


\section{MAGNESIUM, IMMUNE RESPONSES, AND OXIDATIVE STRESS}

There is evidence that $\mathrm{Mg}$ plays a role in the immune response. Magnesium has a strong relationship with the immune system, in both non-specific and specific immune responses, while magnesium deficit has been shown to be related to impaired cellular and humoral immune function. Magnesium deficiency leads to immunopathologic changes that are related to the initiation of a sequential inflammatory response. Magnesium is a cofactor for immunoglobulin (Ig) synthesis, immune cell adherence, antibody-dependent cytolysis, IgM lymphocyte binding, macrophage response to lymphokines, and T helper- $\beta$ cell adherence. ${ }^{45,46}$ In addition, Mg deficiency seems to accelerate thymus involution. One of the most remarkable results regarding the effects of $\mathrm{Mg}$ deficiency on the organism is the higher level of apoptosis shown in thymuses from Mg-deficient rats as compared with controls. ${ }^{47}$ Altered polymorphonuclear (PMN) cell number and function have been shown in rats fed a $\mathrm{Mg}$-deficient diet for 8 days, together with the characteristic inflammatory response. In fact, an increased number of neutrophils, related to an increased activity of phagocytosis, has been found in Mg-deficient rats compared with control rats. ${ }^{48}$ Clinical signs of inflammation, splenomegaly, and leukocytosis, have been reported as well in rats given a $\mathrm{Mg}$-deficient diet. A reduced proportion of CD8-T cells has been shown under these conditions, which has been related to a decreased concentration of interferon (IFN) $-\gamma$ in spleen homogenates. ${ }^{49}$ Several changes in gene expression, including upregulation of TNF receptor 1 and IL-1 receptor type I, have also been demonstrated in rat thymocytes in early $\mathrm{Mg}$ deficiency. ${ }^{21} \mathrm{~A}$ recent study discovered a key role for $\mathrm{Mg}$ in the $\mathrm{T}$ cell antigen receptor signaling pathway from the study of a novel primary immunodeficiency. ${ }^{50}$ There are studies confirming the involvement of $\mathrm{Mg}$ in human cell apoptosis. Fas-induced $\beta$-cell apoptosis is Mg-dependent. Increased cytosolic free Mg levels are required for Fas molecule binding expression on the $\beta$-cell surface to initiate multiple signaling pathways that result in apoptotic cell death. ${ }^{51}$ In vitro incubation of granulocytes in media with different $\mathrm{Mg}$ composition resulted in significant changes in chemotactic peptideinduced calcium transients. ${ }^{52}$

Because physical exercise may deplete $\mathrm{Mg}$, many aspects of immune function can be depressed temporarily by either severe exercise or a longer period of excessive training. ${ }^{53}$ Although the disturbance is usually quite transient, it has been suggested that it may be sufficient to allow clinical episodes of infection, particularly upper respiratory tract infections..$^{53}$ The risk may be higher in older persons who already have a reduced immune capacity and a consequent propensity to infections. However, regular and moderate exercise has been reported to improve the ability of the immune system to protect the host from infection. ${ }^{53}$ Strenous exercise has been associated with an acute increase in oxidative stress free radical (ROS) production. ${ }^{13}$ ROS may contribute to the development of muscle fatigue in situ, but there is still a lack of convincing direct evidence that ROS are able to impair exercise performance in vivo in humans. It remains unclear whether exercise-induced oxidative stress modifications may have clinical significance. Conversely, the antioxidant actions of $\mathrm{Mg}^{26}$ may have a role in muscle protection in the aging population. Even though this needs to be proven by specific trials, it is likely that maintaining a good quality $\mathrm{Mg}$ homeostasis throughout life, and in particular in older persons, may help to protect from muscle performance decline associated with aging.

\section{CONSEQUENCES OF MAGNESIUM IMBALANCE WITH AGE}

The consequences of $\mathrm{Mg}$ imbalance in elderly people related to defective membrane function, chronic inflammation, increased oxidative stress, and immune dysfunction may include an increased vulnerability to age-related diseases and particularly to sarcopenia and frailty.

Several studies have reported alterations in cell physiology with senescence features during $\mathrm{Mg}$ deficiency in different cell types. Magnesium is an essential cofactor in cell proliferation and differentiation and in all steps of nucleotide excision repair. Magnesium deficiencyrelated alterations may include reduced oxidative stress defense, cell cycle progression, culture growth, cellular viability, $44-57$ activation of proto-oncogenes (i.e. c-fos, c-jun), and expression of transcription factors (e.g. $\mathrm{NF \kappa B}){ }^{58}$ Magnesium deficiency may accelerate cellular senescence in cultured human fibroblasts. Continuous culture of primary fibroblasts in $\mathrm{Mg}$-deficient media resulted in the loss of replicative capacity with accelerated expression of senescence-associated biomarkers. A marked decrease in the replicative lifespan was seen compared to fibroblast populations cultured in standard Mg media conditions. Human fibroblast populations cultured in $\mathrm{Mg}$-deficient conditions also showed an increased senescence-associated $\beta$-galactosidase activity. Additionally, activation of cellular aging (p53 and pRb) pathways by $\mathrm{Mg}$-deficient conditions also increased the expression of proteins associated with cellular senescence, including p16INK4a and p21WAF1. Telomere attrition was found to be accelerated in cellular populations from $\mathrm{Mg}$-deficient cultures, suggesting that the long-term consequence of inadequate $\mathrm{Mg}$ availability in human fibroblast cultures is an accelerated cellular senescence. ${ }^{59}$ Features of cellular senescence induced by low magnesium concentrations have also been reported in other cell types, e.g. endothelial cells. ${ }^{60}$ Intracellular free $\mathrm{Mg}$ is a 'second messenger' for downstream events in apoptosis. There is increasing evidence from animal 


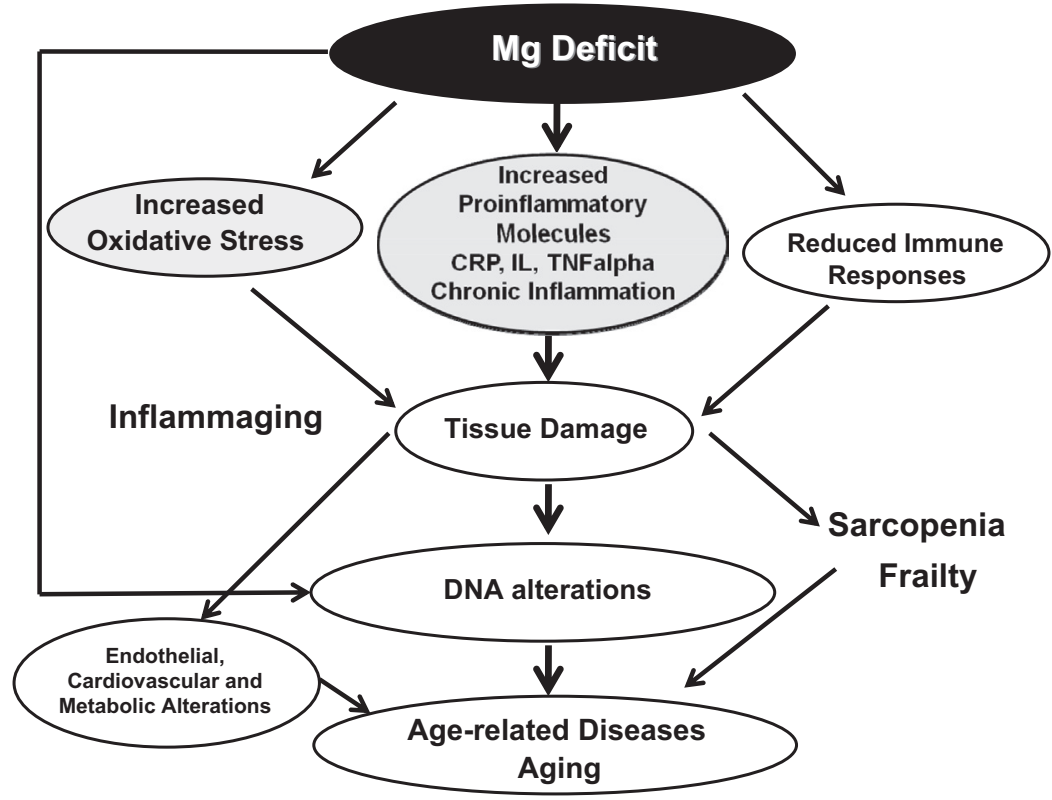

FIGURE 16.2 Overall hypothesis in which a chronic $\mathrm{Mg}$ deficit has been proposed as one of the physiopathologic links that may help to explain the interactions among inflammation, oxidative stress, and altered immune responses with sarcopenia of aging and with the aging process. experiments and epidemiologic studies that $\mathrm{Mg}$ deficiency may decrease membrane integrity and membrane function, increasing the susceptibility to oxidative stress, cardiovascular disease, and accelerated aging. It is likely that many of these $\mathrm{Mg}$ effects may have relevance also to the aging of muscle and sarcopenia, as well as to many other age-related diseases.

\section{CONCLUSIONS}

Aging is very often associated with $\mathrm{Mg}$ inadequacy. Chronic Mg deficiency may result in excessive production of oxygen-derived free radicals. Oxidative stress and a chronic, low-grade inflammation have been proposed as an underlying condition linked to aging muscle, sarcopenia, and frailty. A chronic Mg deficit has been proposed as one of the physiopathologic mechanisms that may help to explain the interactions among inflammation and oxidative stress with sarcopenia, frailty, and a number of age-related diseases (Figs 16.2 and 16.3).

Magnesium status is strictly connected to muscle performance in older persons. A possible mechanism of this association is the effect of $\mathrm{Mg}$ concentrations on mitochondrial function in muscle, which may be particularly critical in the aging muscle.

Despite the physiologic importance of $\mathrm{Mg}$, the multiple problems associated with its deficiency, and the ease of supplementation, inadequate $\mathrm{Mg}$ intake remains highly prevalent in various populations. Because $\mathrm{Mg}$ supplementation is inexpensive and in general well tolerated, it should be a key consideration in older subjects at particular risk for $\mathrm{Mg}$ deficiency. Although existing data confirm that the availability of an adequate quantity of $\mathrm{Mg}$ is a critical factor for normal cellular and body homeostasis, much remains to be done in this field to further clarify the potential role of $\mathrm{Mg}$ supplementation.

Even if the role of $\mathrm{Mg}$ supplementation as a possible intervention approach for delaying or preventing muscle aging deserves some consideration, a number of questions still need to be answered. What is the role of oxidative stress and inflammatory cytokines in mediating the adverse effect of $\mathrm{Mg}$ deficiency on muscle? Is low $\mathrm{Mg}$ a component of the frailty syndrome leading to sarcopenia of aging? Can $\mathrm{Mg}$ supplementation influence muscle strength/performance and cytokine concentrations in older persons? The possible role of $\mathrm{Mg}$ supplementation in aging-associated conditions remains unclear. At present, there are no data to support a potential role of dietary $\mathrm{Mg}$ supplementation as a possible health strategy in the aging population. Very few open and double-blind studies on the effects of the treatment of $\mathrm{Mg}$ deficiencies in geriatric populations have been done. The possibility that maintaining an optimal $\mathrm{Mg}$ balance throughout life might help in preventing or significantly retarding the oxidative stress and inflammation process, and the manifestations of chronic diseases, including sarcopenia and frailty, is a working hypothesis that needs to be tested in future prospective studies.

\section{SUMMARY POINTS}

- $\mathrm{Mg}$ is a key intracellular cation because it is an essential cofactor in a wide variety of biologic processes, including protein synthesis, nucleic acid synthesis and stability, neuromuscular excitability and conduction of neural impulses, stimuluscontraction coupling, and muscle contraction; it is also an antioxidant. 


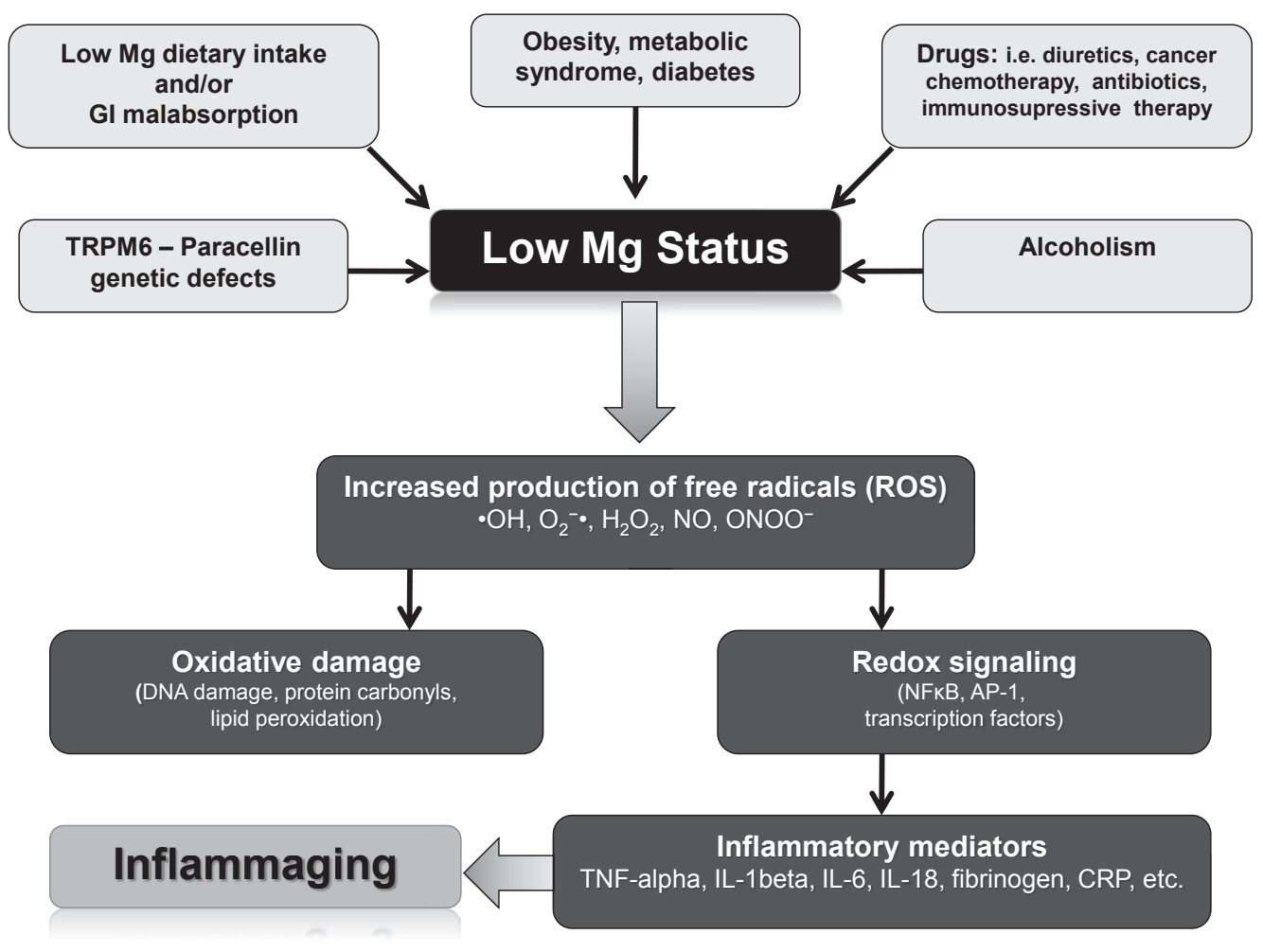

FIGURE 16.3 Low $\mathrm{Mg}$ status has different determinants that may converge in old age. Because $\mathrm{Mg}$ reduces the production of free radicals by the mitochondria as an antioxidant, its deficit may lead to the accumulation of oxidative damage and the release of inflammatory mediators. These events have been identified as 'inflammaging', that is, the low-grade chronic inflammation frequently seen in old age, which is associated with age-related conditions.

vith age-related conditions. 
15. Barbagallo M, Dominguez LJ. Magnesium and aging. Curr Pharmaceut Design 2010;16:832-9.

16. Dickens BF, Weglicki WB, Li YS, Mak IT. Magnesium deficiency in vitro enhances free radical-induced intracellular oxidation and cytotoxicity in endothelial cells. FEBS Lett 1992;311: 187-91.

17. Freedman AM, Mak IT, Stafford RE, et al. Erythrocytes from magnesium-deficient hamsters display an enhanced susceptibility to oxidative stress. Am J Physiol 1992;262:C1371-5.

18. Weglicki WB, Mak IT, Kramer JH, et al. Role of free radicals and substance P in magnesium deficiency. Cardiovasc Res 1996;31: 677-82.

19. Mazur A, Maier JA, Rock E, et al. Magnesium and the inflammatory response: potential physiopathological implications. Arch Biochem Biophys 2007;458:48-56.

20. Blache D, Devaux S, Joubert O, et al. Long-term moderate magnesium-deficient diet shows relationships between blood pressure, inflammation and oxidant stress defense in aging rats. Free Rad Biol Med 2006;41:277-84.

21. Petrault I, Zimowska W, Mathieu J, et al. Changes in gene expression in rat thymocytes identified by cDNA array support the occurrence of oxidative stress in early magnesium deficiency. Biochim Biophys Acta 2002;1586:92-8.

22. Rayssiguier Y, Durlach J, Gueux E, et al. Magnesium and ageing. I. Experimental data: importance of oxidative damage. Magnes Res 1993;6:369-78.

23. Yang Y, Wu Z, Chen Y, et al. Magnesium deficiency enhances hydrogen peroxide production and oxidative damage in chick embryo hepatocyte in vitro. Biometals 2006;19:71-81.

24. Calviello G, Ricci P, Lauro L, et al. Mg deficiency induces mineral content changes and oxidative stress in rats. Biochem Mol Biol Int 1994;32:903-11.

25. Touyz RM, Pu Q, He G, et al. Effects of low dietary magnesium intake on development of hypertension in stroke-prone spontaneously hypertensive rats: role of reactive oxygen species. J Hypertens 2002;20:2221-32.

26. Afanas'ev IB, Suslova TB, Cheremisina ZP, et al. Study of antioxidant properties of metal aspartates. Analyst 1995;120: 859-62.

27. Hans CP, Chaudhary DP, Bansal DD. Effect of magnesium supplementation on oxidative stress in alloxanic diabetic rats. Magnes Res 2003;16:13-9.

28. Barbagallo M, Dominguez LJ, Tagliamonte MR, et al. Effects of glutathione on red blood cell intracellular magnesium: relation to glucose metabolism. Hypertension 1999;34:76-82.

29. Barbagallo M, Dominguez LJ, Tagliamonte MR, et al. Effects of vitamin E and glutathione on glucose metabolism: role of magnesium. Hypertension 1999a;34:1002-6.

30. Ferrucci L, Guralnik JM. Inflammation, hormones, and body composition at a crossroad. Am J Med 2003;115:501-2.

31. Weglicki WB, Dickens BF, Wagner TL, et al. Immunoregulation by neuropeptides in magnesium deficiency: ex vivo effect of enhanced substance P production on circulation T lymphocytes from magnesium-deficient mice. Magnes Res 1996;9:3-11.

32. Kramer JH, Mak IT, Phillips TM, Weglicki WB. Dietary magnesium intake influences circulating pro-inflammatory neuropeptide levels and loss of myocardial tolerance to postischemic stress. Exp Biol Med 2003;228:665-73.

33. Maier JAM, Malpuech-Brugère $C$, Zimowska W, et al. Low magnesium promotes endothelial cell dysfunction: implications for atherosclerosis, inflammation and thrombosis. Biochim Biophys Acta 2004;1689:13-21.

34. Bernardini D, Nasulewicz A, Mazur A, Maier JAM. Magnesium and microvascular endothelial cells: a role in inflammation and angiogenesis. Front Biosci 2005;10:1177-82.
35. Barbagallo M, Dominguez LJ, Resnick LM. Magnesium metabolism in hypertension and type 2 diabetes mellitus. Am J Clin Ther 2007;14:375-85.

36. Malpuech-Brugere C, Nowacki W, Daveau M, et al. Inflammatory response following acute magnesium deficiency in the rat. Biochim Biophys Acta 2000;1501:91-8.

37. Weglicki WB, Phillips TM. Pathobiology of magnesium deficiency: a cytokine/neurogenic inflammation hypothesis. Am J Physiol 1992;263:R734-7.

38. Kurantsin-Mills J, Cassidy MM, Stafford RE, Weglicki WB. Marked alterations in circulating inflammatory cells during cardiomyopathy development in a magnesium-deficient rat model. Br J Nutr 1997:78:845-55.

39. Bussiere FI, Tridon A, Zimowska W, et al. Increase in complement component $\mathrm{C} 3$ is an early response to experimental magnesium deficiency in rats. Life Sci 2003;73:499-507.

40. Oono $\mathrm{H}$, Nakagawa M, Miyamoto A, et al. Mechanisms underlying the enhanced elevation of IL-1beta and TNF-alpha mRNA levels following endotoxin challenge in rat alveolar macrophages cultured with low-Mg2+ medium. Magnes Res 2002;15:153-60.

41. Song Y, Ridker PM, Manson JE, et al. Magnesium intake, C-reactive protein, and the prevalence of metabolic syndrome in middleaged and older U.S. women. Diabetes Care 2005;28:1438-44.

42. King DE, Mainous 3rd AG, Geesey ME, Woolson RF. Dietary magnesium and C-reactive protein levels. J Am Coll Nutr 2005;24:166-71.

43. Guerrero-Romero F, Rodriguez-Moran M. Hypomagnesemia, oxidative stress, inflammation, and metabolic syndrome. Diabetes Metab Res Rev 2006;22:471-6.

44. Rodriguez-Moran M, Guerrero-Romero F. Elevated concentrations of TNF-alpha are related to low serum magnesium levels in obese subjects. Magnes Res 2004;17:189-96.

45. Galland L. Magnesium and immune function: an overview. Magnesium 1988;7:290-9.

46. Tam M, Gomez S, Gonzalez-Gross M, Marcos M. Possible roles of magnesium on the immune system. Eur J Clin Nutr 2003;57:1193-7.

47. Malpuech-Brugere C, Nowacki W, Gueux E, et al. Accelerated thymus involution in magnesium-deficient rats is related to enhanced apoptosis and sensitivity to oxidative stress. $\mathrm{Br} J \mathrm{Nutr}$ 1999;81:405-11.

48. Bussiere FI, Gueux E, Rock E, et al. Increased phagocytosis and production of reactive oxygen species by neutrophils during magnesium deficiency in rats and inhibition by high magnesium concentration. Br J Nutr 2002;87:107-13.

49. Malpuech-Brugere C, Kuryszko J, Nowacki W, et al. Early morphological and immunological alterations in the spleen during magnesium deficiency in the rat. Magnesium Res 1998;11:161-9.

50. Li FY, Chaigne-Delalande B, Kanellopoulou C, et al. Signaling role for $\mathrm{Mg}^{2+}$ revealed by immunodeficiency due to loss of MagT1. Nature 2011;475:471-6.

51. Chien MM, Zahradka KE, Newell MK, Freed JH. Fas-induced B cell apoptosis requires an increase in free cytosolic magnesium as an early event. J Biol Chem 1999;274:7059-66.

52. Mooren FC, Golf SW, Völker K. Effect of magnesium on granulocyte function and on the exercise inflammatory response. Magnes Res 2003;16:49-58.

53. Laires MJ, Monteiro C. Exercise, magnesium and immune function. Magnes Res 2008;21:92-6.

54. McKeehan WL, Ham RG. Calcium and magnesium ions and the regulation of multiplication in normal and transformed cells. $\mathrm{Na}$ ture 1978;275:756-8.

55. Ames BN, Atamna H, Killilea DW. Mineral and vitamin deficiencies can accelerate the mitochondrial decay of aging. Mol Aspects Med 2005;26:363-78.

56. Hartwig A. Role of magnesium in genomic stability. Mutat Res 2001;475:113-21. 
57. Sgambato A, Wolf FI, Faraglia B, Cittadini A. Magnesium depletion causes growth inhibition, reduced expression of cyclin D1, and increased expression of P27Kip1 in normal but not in transformed mammary epithelial cells. J Cell Physiol 1999;180:245-54.

58. Altura BM, Kostellow AB, Zhang A, et al. Expression of the nuclear factor-kappaB and proto-oncogenes c-fos and c-jun are induced by low extracellular $\mathrm{Mg}^{2+}$ in aortic and cerebral vascular smooth muscle cells: possible links to hypertension, atherogenesis, and stroke. Am J Hypertens 2003;16:701-7.
59. Killilea DW, Ames BN. Magnesium deficiency accelerates cellular senescence in cultured human fibroblasts. Proc Natl Acad Sci USA 2008;105:5768-73.

60. Ferre S, Mazur A, Maier JAM. Low magnesium induces senescent features in cultured human endothelial cells. Magnes Res 2007;20:66-71. 